\title{
Uterine Horn
}

National Cancer Institute

\section{Source}

National Cancer Institute. Uterine Horn. NCI Thesaurus. Code C161570.

The portion of the reproductive tract that connects the fallopian tubes to the uterus. The prominence of the uterine horns are variable across species and may be the location at which embryo implantation occurs in some species. 